\title{
DSREM REGULATOR IN THE TCP/IP NETWORK
}

\author{
Timur Dovzhenko \\ Department of Switching Systems \\ State University of Telecommunications \\ 17 Uborevycha str., Kyiv, Ukraine, 03179 \\ evetal1992@ukr.net
}

\begin{abstract}
The paper presents the main parameters and describes the behavior of the active queue management (AQM) algorithm which based on random exponential marking (REM) packets in TCP/IP network. It has presented the new AQM algorithm, which has been developed by author, which is based on REM and uses dynamically splitting marking characteristic (DSREM) of network packets. The basic parameters and functional principle of DSREM algorithm have been shown. Block diagram of linearized AQM system, which is based on DSREM management law and describes its main components, is shown. Transfer characteristic for DSREM, which is based on the Laplace transform and its basic parameters, are considered. Simulation of TCP/IP network, which contains congested link for small and large sources of incoming messages using REM and DSREM regulators, is done. Log-frequency characteristics for REM and DSREM methods are obtained and their comparative analysis is performed. It is concluded that the regulator based on DSREM algorithm has better performance and stability of the system can be used in the AQM system.
\end{abstract}

Keywords: active queue management, TCP/IP network, REM, DSREM, AQM regulator log frequency characteristic.

\section{Introduction}

Router buffer queue is observed when the stochastic and uncontrolled growth of data channel rate, and thus congestion of link. Traditional protocols for queue management and congestion prevention can't cope with the traffic management with complex dynamics, non-linear load change that leads to congestion and the emergence of the phenomenon of global synchronization of TCP flows. This, in turn, reduces the effective data rate and worsens the quality parameters, such as the percentage of lost packets, delay and delay variation. Today, a significant number of algorithms were developed to deal with queue congestion. Methods of active queue management (AQM) are used to avoid increasing the router buffer queue and, consequently, congestion of TCP/IP networks [1].

Analysis of research [2-7] indicates the urgency of developing improved methods of AQM system for improving performance of stability parameters during rapid load changes in the network.

Most AQM methods are not able to effectively maintain system stability of active queue management with a significant increase in traffic in the network and thereby provide a sufficient level of quality indicators.

The aim of this work is to improve the stability performances of the active queue management by constructing AQM system regulator on the basis of modified REM (Random Exponential Marking) algorithm, which is one of the most effective AQM methods.

\section{Materials and Methods}

Random exponential marking (REM) method uses exponential control law, which uses the congestion measure $\mathrm{p}$ as an argument at a certain point in time $\mathrm{kT}$ and calculated by the formula [8]:

$$
p(k)=\max \left(0, p((k-1) T)+\gamma\left(\alpha\left(q(k T)-q_{r e f}\right)+x(k T)-c\right)\right)
$$

where c-channel capacity; $\mathrm{q}(\mathrm{kT})$ - current length of router buffer queue; $\mathrm{x}(\mathrm{kT})$ - packet arrival rate; a and $\gamma$-a constant greater than zero ( 0.1 and 0.001 , respectively); $\mathrm{T}$ - interval of measurements; $\mathrm{k}$ - number of interval. 
Each output packet contains the variable (measure) $\mathrm{p}(\mathrm{kT})$, which stores information about network congestion. This parameter is used to determine the likelihood of packet discarding/marking and calculated as follows:

$$
\operatorname{prob}(\mathrm{kT})=1-\varphi^{-\mathrm{p}(\mathrm{kT})}
$$

where $\varphi$ - constant greater than one (1.001).

Operation of REM algorithm is shown in Fig. 1, $\boldsymbol{a}, \boldsymbol{b}$.
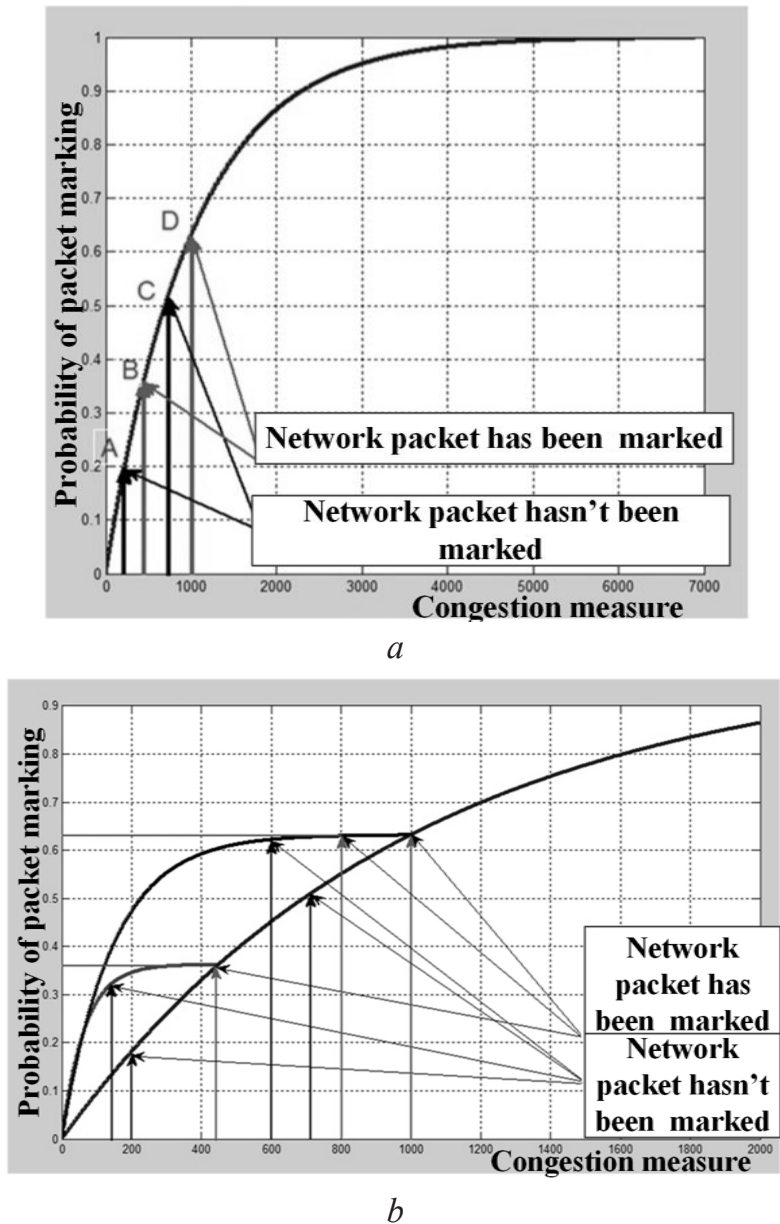

Fig. 1. Graph of dependency of packet marking probability from the congestion measure of the channel: $a$ - for DSREM method; $b$ - for REM method

Every time during packet arrival in queue its measure and probability of marking are changed. If there is a light load on the network, a packet that has some index (measure) of congestion corresponding point A and the probability of marking to that point, was not marked, then the window of the receiver will increase by 2 times, and thus increase the congestion in the TCP/IP network. The next packet with corresponding performance in point $\mathrm{B}$ can be marked or discarded. Then window of the receiver reduced with congestion in the network. If the next packet (at point $\mathrm{C}$ ) will have greater values of probability of marking and congestion measure, but will not be discarded, the network congestion will increase again and the next packet can be discarded with a high probability.

DSREM algorithm is a modification of REM algorithm. The principle of the algorithm is illustrated in Fig. 1, b. At the start, when the congestion on the network is absence or low, DSREM algorithm operates according to REM algorithm: if the first packet wasn't discarded, window of transmitter increases by 2 times, thereby increasing packet transmission and congestion. Let the next packet will be marked. Then the probability characteristics will be split due to the zoom ratio 
along the axis of probability $\mathrm{k} 1$ and axis of congestion measure $\mathrm{k} 2$ [9]. These coefficients are determined by the formulas:

$$
\begin{gathered}
\mathrm{k} 1=\left(1-\varphi^{{ }^{*} \mathrm{p}_{-} \max }\right), \\
\mathrm{k} 2=\mathrm{p}_{-} \mathrm{max}_{\text {_const }} / \mathrm{p}_{-} \text {max }
\end{gathered}
$$

where $\mathrm{p}_{-}$max _ const $=6911$ - value of marking measure with the probability of packet discarding 0,$999 ; p_{-}$max - Maximum measure value at each iteration; $\varphi^{*}-$ value of parameter for losses at each iteration, which is defined by:

$$
\varphi^{*}=1+(\varphi-1) / \mathrm{k}_{\mathrm{st}} .
$$

Then the probability of marking for DSREM algorithm can be written as

$$
\operatorname{prob}(\mathrm{kT})=\mathrm{k} 1 \cdot\left(1-\varphi^{*-\mathrm{k} 2 \cdot \mathrm{p}(\mathrm{kT})}\right)
$$

The measure for the next packet is reduced according to load in the network, but the probability of packet marking is calculated by split characteristic of probability. When the congestion increases, the probability is calculated using REM method. In addition, if the next packet after splitting probability characteristics was not marked and has a lower measure, the probability of rejection for it will also calculated using split characteristics.

Thus, decreasing input router flows, DSREM reduces the probability of discarding packets slower than REM algorithm, thus preventing queue growth in the buffer.

DSREM algorithm in TCP/IP network can be used as a queue regulator in the feedback loop.

Formula (5) includes specially defined coefficient $\mathrm{k}_{\mathrm{st}}$. It plays an important role in the construction of the transfer function DSREM regulator and defining quality indicators of transfer characteristics of the closed transfer function of TCP network.

The stability coefficient $\mathrm{k}_{\mathrm{st}}$ is determined by the following algorithm:

1. Find the frequency $\mathrm{w}$ at which the value of the logarithmic phase characteristics satisfies the qualitative indicators of the transfer process. To do this, we solve the following equation:

$$
\mathrm{P}(\mathrm{w}) \operatorname{tg} \theta-\mathrm{Q}(\mathrm{w})=0
$$

where $\mathrm{P}(\mathrm{w})$ - the actual part of transfer function of the open-loop system; $\mathrm{Q}(\mathrm{w})$ - imaginary part of transfer function of the open-loop system; $\operatorname{tg} \theta$ - tangent of the angle at which the transfer function satisfies quality score.

2. Determine module of amplitude and phase characteristics for obtained frequency:

$$
\mathrm{A}(\mathrm{w})=\sqrt{\mathrm{P}^{2}(\mathrm{w})+\mathrm{Q}^{2}(\mathrm{w})} .
$$

3. Determine the stability coefficient:

$$
\mathrm{k}_{\mathrm{st}}=\sqrt{\mathrm{A}(\mathrm{w})}
$$

The algorithm of DSREM method consists of the following steps:

1. If the sum of the previous and the current measure is less or equal to zero, and probability for packet marking/discarding will also be zero.

2 . If the sum is more than parameter $p_{-} \max$ that parameter $p_{-} \max$ is set to measure value, and the probability of packet discarding is calculated by the formula (6).

3. If the measure is more than the constant $p_{-}$max _ const, that $p$ is set to the current measure of iteration without previous values, and variable increases.

4. When the measure $p$ is less than $p_{-} \max$, that the variable $\varphi^{*}$ decreases and marking probability $\operatorname{prob}(\mathrm{kT})$ is calculated by the formula (6). 
Fig. 2 shows a block diagram of an active queue management with feedback and AQM management law adjusted by DSREM regulator [10].

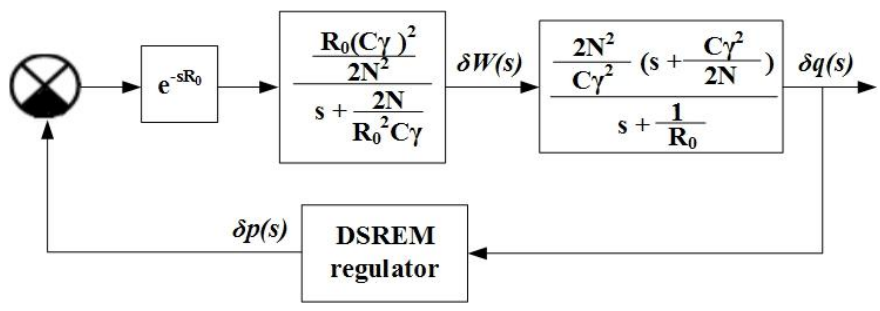

Fig. 2. Block diagram of linearized AQM system with DSREM management law

where $\delta \mathrm{q}=\mathrm{q}_{0}-\mathrm{q}, \mathrm{p}=\mathrm{p}_{0}+\delta \mathrm{p}, \mathrm{q}_{0}, \mathrm{p}_{0}$ - the length of queues and the probability of packet marking/discarding at the operating point; $\mathrm{e}^{-\mathrm{sR}_{0}}-$ transfer function of delay link; $\frac{\frac{\mathrm{R}_{0}(\mathrm{C} \gamma)^{2}}{2 \mathrm{~N}^{2}}}{2 \mathrm{~N}}-$ transfer function of TCP element; $\frac{\frac{2 \mathrm{~N}^{2}}{\mathrm{C} \gamma^{2} \mathrm{R}_{0}}\left(\mathrm{~s}+\frac{\mathrm{C} \gamma^{2}}{2 \mathrm{~N}}\right)}{\mathrm{s}+\frac{1}{\mathrm{R}_{0}}}-$ transfer function of queue element.

Dynamics of the object is described by transfer function, which is the Laplace ratio of variable "queue length" variable to "probability of packet discarding/marking" variable for sustainable mode as:

$$
\mathrm{G}(\mathrm{s})=\mathrm{P}(\mathrm{s}) \mathrm{e}^{-\mathrm{sR}_{0}}=\frac{\delta \mathrm{q}(\mathrm{s})}{\delta \mathrm{p}(\mathrm{s})}=\frac{\delta \mathrm{W}(\mathrm{s})}{\delta \mathrm{p}(\mathrm{s})} \cdot \frac{\delta \mathrm{q}(\mathrm{s})}{\delta \mathrm{W}(\mathrm{s})}=\frac{-\mathrm{e}^{-\mathrm{sR}_{0}} \frac{\mathrm{R}_{0} \mathrm{C}^{2}}{2 \mathrm{~N}^{2}}}{\mathrm{~s}+\frac{2 \mathrm{~N}}{\mathrm{CR}_{0}^{2}}} \cdot \frac{\frac{\mathrm{N}}{\mathrm{R}_{0}}}{\mathrm{~s}+\frac{1}{\mathrm{R}_{0}}}
$$

where $q$ - queue length (in packets); $p$ - probability of packet marking/discarding; $s=\sigma+j \omega-$ complex number; $\mathrm{C}$ - channel capacity (packets/s); $\mathrm{N}$ - load coefficient (the number of TCP sessions); $\mathrm{T}_{\mathrm{p}}$ - propagation delay ( $\left.\mathrm{s}\right) ; \mathrm{R}_{0}$ - Round trip time is calculated using the formula:

$$
\mathrm{R}_{0}=\frac{\mathrm{q}}{\mathrm{C}}+\mathrm{T}_{\mathrm{p}}
$$

Ratio $\frac{\delta \mathrm{W}(\mathrm{s})}{\delta \mathrm{p}(\mathrm{s})}-$ transfer function that describes the dynamics of TCP window control mechanism.

The transfer function $\frac{\delta \mathrm{q}(\mathrm{s})}{\delta \mathrm{W}(\mathrm{s})}$ describes the queue dynamics.

Rate of marking packets at sustainable mode is defined as:

$$
\lambda_{0}=\frac{2 \mathrm{~N}}{\mathrm{R}_{0}^{2} \mathrm{C}},
$$

where $\frac{2 \mathrm{~N}}{\mathrm{R}_{0}^{2} \mathrm{C}}$ and $\frac{1}{\mathrm{R}_{0}}-$ the eigenvalues of the linearized TCP and queue dynamics. function:

The transfer function of delay link function can be approximated by second order Pade

$$
\mathrm{e}^{-\mathrm{sR}_{0}} \approx \frac{\mathrm{s}^{2}-\frac{6}{\mathrm{R}_{0}} \mathrm{~s}+\frac{12}{\mathrm{R}_{0}^{2}}}{\mathrm{~s}^{2}+\frac{6}{\mathrm{R}_{0}} \mathrm{~s}+\frac{12}{\mathrm{R}_{0}^{2}}}
$$


Taking into account (13), the transfer function of control object (12) can be represented as follows:

$$
G(s)=P(s) e^{-s R_{0}}=\frac{\frac{C^{2}}{2 N}\left(s^{2}-\frac{6}{R_{0}} s+\frac{12}{R_{0}^{2}}\right)}{\left(s+\frac{2 N}{R_{0}^{2} C}\right)\left(s+\frac{1}{R_{0}}\right)\left(s^{2}+\frac{6}{R_{0}} s+\frac{12}{R_{0}^{2}}\right)} .
$$

The transfer function for REM algorithm can be represented as follows:

$$
\mathrm{G}(\mathrm{s})=\mathrm{b} \gamma+\gamma \alpha \mathrm{b} / \mathrm{h} \cdot 1 / \mathrm{s}
$$

where $\mathrm{b}=\ln \varphi ; \mathrm{h}-$ updating period.

Taking into account the adding of coefficients $\mathrm{k} 1, \mathrm{k} 2$ та $\mathrm{k}_{\mathrm{st}}$ into DSREM algorithm, the transfer function for DSREM algorithm will be as follows:

$$
\mathrm{G}(\mathrm{s})=\mathrm{k} 1 \mathrm{k} 2 \mathrm{~b} \frac{\gamma}{\mathrm{k}_{\mathrm{st}}}+\frac{\mathrm{k} 1 \mathrm{k} 2 \alpha \mathrm{b} \frac{\gamma}{\mathrm{k}_{\mathrm{st}}}}{\mathrm{h}} \cdot \frac{1}{\mathrm{~s}} .
$$

Inserting into (16) instead of $\mathrm{b} \ln \varphi^{*}$ obtain:

$$
\mathrm{G}(\mathrm{s})=\mathrm{k} 1 \mathrm{k} 2 \ln \varphi^{*} \frac{\gamma}{\mathrm{k}_{\mathrm{st}}}+\frac{\mathrm{k} 1 \mathrm{k} 2 \alpha \ln \varphi^{*} \frac{\gamma}{\mathrm{k}_{\mathrm{st}}}}{\mathrm{h}} \cdot \frac{1}{\mathrm{~s}}
$$

After series of transformations get:

$$
\mathrm{G}(\mathrm{s})=\mathrm{k} 1 \mathrm{k} 2 \ln \varphi^{*} \frac{\gamma}{\mathrm{k}_{\mathrm{st}}}(\mathrm{s}+\alpha) \cdot \frac{1}{\mathrm{~s}} .
$$

Amplification coefficient for DSREM transfer function can be written as:

$$
\mathrm{K}_{\mathrm{A}}=\mathrm{k} 1 \mathrm{k} 2 \ln \varphi^{*} \frac{\gamma}{\mathrm{k}_{\mathrm{st}}} .
$$

Then, taking into account (18) and (19) get:

$$
\mathrm{G}(\mathrm{s})=\mathrm{K}_{\mathrm{A}}(\mathrm{s}+\alpha) \cdot \frac{1}{\mathrm{~s}},
$$

where $\mathrm{s}+\alpha$-differential link of the first kind; 1 / s - ideal integrating link.

Stability margin of closed-loop system are determined by the logarithmic characteristics of open-loop system.

\section{Experimental procedures}

Simulation of TCP/IP network that includes congested channel using AQM REM and DSREM algorithms in Simulink are conducted in the article. Network scheme (Fig. 3) consists of 100 FTP message sources that transfer information to TCP receiver using two routers.

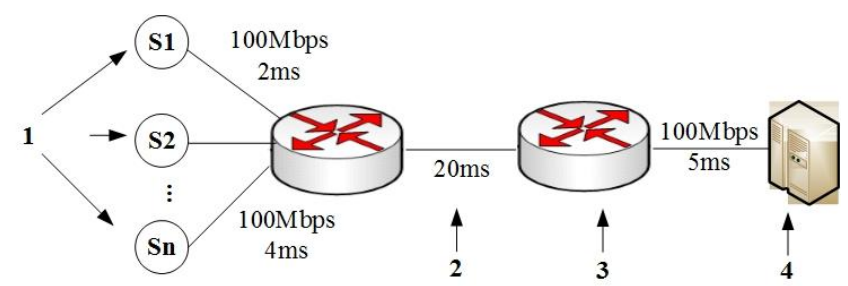

Fig. 3. Network scheme for simulation: 1 - message source, 2 - congested line, 3 - router, $4-\mathrm{TCP}$ receiver of the message 
Channel rate between end nodes and routers is $100 \mathrm{MB} / \mathrm{s}$, delay for each end node is random. Channel rate between two transfer routers is $5 \mathrm{MB} / \mathrm{s}$ (congested channel), and delay - $20 \mathrm{~ms}$.

The first 20 sources start at zero second. After 20 seconds - 40 sources. After 40 seconds - another 40 sources. The duration of the simulation process is 60 seconds.

\section{Results of research}

Fig. 4, 5 presents data of logarithm amplitude and phase and transfer characteristics were obtained by simulating network using REM and DSREM regulators.

\section{The logarithmic amplitude and phase characteristics for REM}

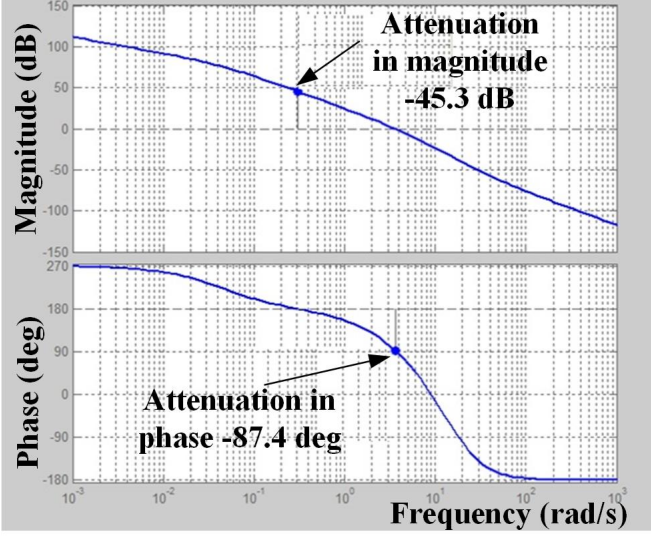

The logarithmic amplitude and phase characteristics for DSREM

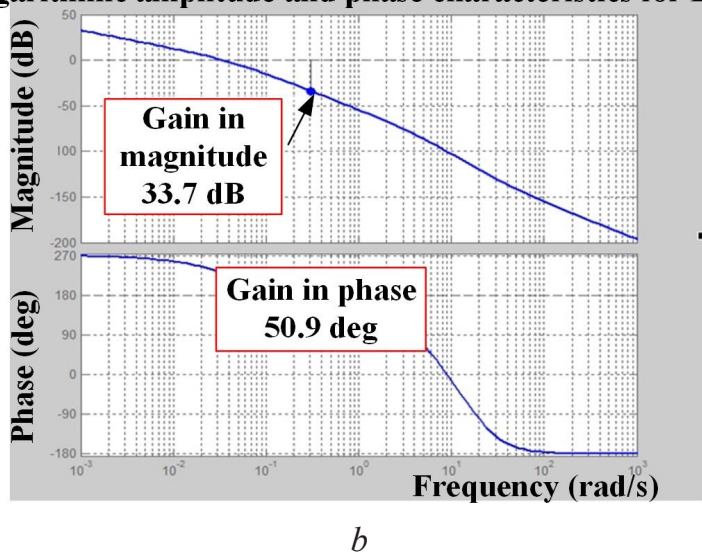

Fig. 4. Logarithm amplitude and phase characteristics: $a$ - for DSREM method; $b$ - for REM method

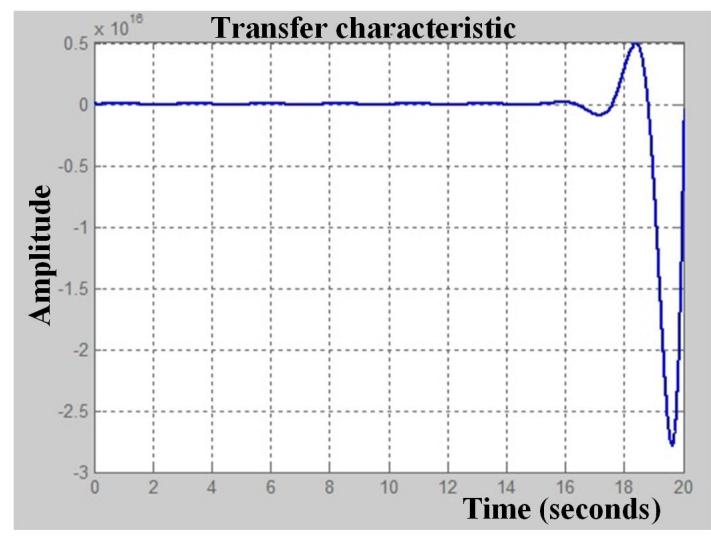

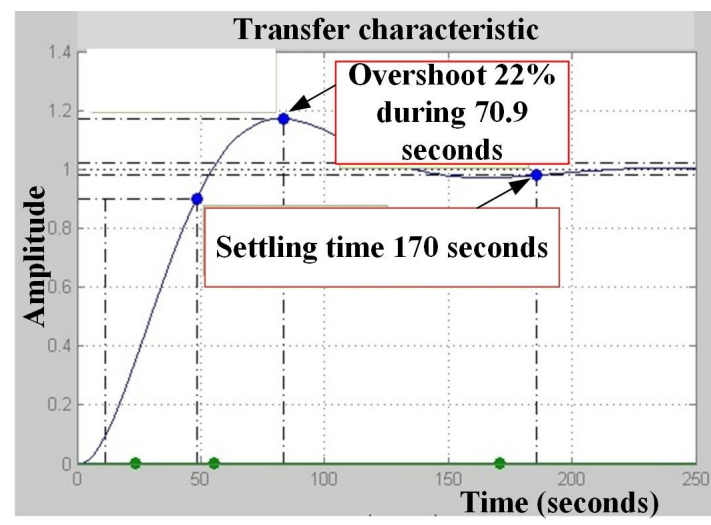

$b$

Fig. 5. Transfer characteristics: $a$ - for REM method; $b$ - for DSREM method 
Fig. $4 \boldsymbol{a}, \boldsymbol{b}$ shows that the system of REM regulator is unstable, while the system of DSREM regulator has sufficient performance amplitude and phase stability margin that fit into the generally accepted norms.

Fig. $5 \boldsymbol{a}, \boldsymbol{b}$ shows that the system of REM regulator is unstable and has increasing amplitude. Overshoot for DRSEM regulator is maintained at the same level (17\%) and has a transfer length of $186 \mathrm{sec}$ and the rise time of $36.8 \mathrm{sec}$.

The value of simulation for logarithm amplitude and phase and transfer characteristics listed in the Tables 1, 2.

Table 1

Parameters of logarithm amplitude and phase characteristics for REM and DSREM

\begin{tabular}{cccccc}
\hline $\begin{array}{c}\text { Channel capacity } \\
\text { of congested } \\
\text { channel, MB/s }\end{array}$ & $\begin{array}{c}\text { Number of input } \\
\text { nodes, units }\end{array}$ & $\begin{array}{c}\text { Amplitude stability } \\
\text { margin, dB }\end{array}$ & $\begin{array}{c}\text { Phase stability } \\
\text { margin, degree }\end{array}$ & $\begin{array}{c}\text { Amplitude stability } \\
\text { margin, dB }\end{array}$ & $\begin{array}{c}\text { Phase stability } \\
\text { margin, degree }\end{array}$ \\
\hline 5 & 5 & 1,7 & 3,85 & 20 & 50,6 \\
5 & 95 & 56,2 & 89,8 & 9,78 & 51,8 \\
30 & 5 & $-45,3 *$ & $-87,4$ & 33,7 & 50,9 \\
30 & 95 & 6,84 & 2,6 & 13,6 & 50,5
\end{tabular}

Note: *-system is unstable for these values

Table 2

Parameters of transfer characteristics for REM and DSREM

\begin{tabular}{cccccccc}
\hline $\begin{array}{c}\text { Channel capacity } \\
\text { of congested } \\
\text { channel, MB/s }\end{array}$ & $\begin{array}{c}\text { Number of input } \\
\text { nodes, units }\end{array}$ & Rise time, s & Overshoot, $\%$ & Setting time, s & Rise time, s & Dvershoot, \% & Setting time, $\mathbf{s}$ \\
\hline 5 & 5 & 1,62 & 89,4 & 183 & 6,74 & 17,2 & 34,4 \\
5 & 95 & & $* *$ & & 36,8 & 17,1 & 186 \\
30 & 5 & 435 & 0 & 776 & 1,01 & 16,9 & 5,33 \\
30 & 95 & 1,4 & 49,2 & 19,5 & 2,61 & 17,4 & 13,6
\end{tabular}

Note: ** - amplitude of the transfer characteristics is unstable and growing

The most effective is the use of regulator on the basis of DSREM algorithm because when compared with REM algorithm, it has the best stability in amplitude and phase, and overshoot and duration of transfer characteristics are more stable character.

\section{Discussion of results}

After analyzing the data, it can assert that the AQM system on the basis of proposed DSREM algorithm is more adapted to the change of input load in TCP/IP network than the system on the basis of REM algorithm. This gives reason to believe the prospects for further application of DSREM algorithm as AQM method for buffer packet queue management of the network router.

\section{Conclusions}

DSREM queue regulator in TCP/IP network allow to stabilize parameters of transfer characteristics when changing network load and maintain a sufficient level of stability of AQM system in magnitude and phase. The method should be used in research centers and design offices of companies for the design and improvement of TCP/IP networks and network switching equipment. 


\section{References}

[1] Kovalenko, A. A., Zavyzystup, Ju. Ju., Partyka, S. A. (2005). Problemy proyzvodyteljnosty protokola TCP v gheteroghennykh setjakh y metody ee uluchshenyja. Vestnyk KhNTU, 1 (21), 305-311.

[2] Floyd, S., Jacobson, V. (1993). Random Early Detection gateways for Congestion Avoidance. IEEE/ACM Transactions on Networking, 1 (4), 397-413.

[3] Hollot, C. V., Misra, V., Towsley, D., Gong, W. B. (2002). Analysis and Design of Controllers for AQM Routers Supporting TCP Flows. IEEE Transactions on Automatic Control, 945-959.

[4] Athuraliya, S., Low, S. H., Li, V. H., Qinghe, Y. (2001). REM: active queue management. IEEE Networking Magazine, 15 (3), 48-53.

[5] Kran, P., Partridge, C. (2005). Improving round-trip time estimates in reliable transport Protocols. ACM Computer Communication, 66-74.

[6] Zhang, H., Hollot, C. V. et al. (2003). A self-tuning structure for adaptation in TCP/AQM networks, ACM SIGMETRICS Performance Evaluation, 302-303.

[7] Papachristodoulou, A., Jadbabaie, A. (2010). Delay Robustness of Nonlinear Internet Congestion Control Schemes. IEEE Transactions on Automatic Control, 55 (6), 1421-1427.

[8] Dovzhenko, T. P., Ghostev, V. Y., Artjushhyk, A. S. (2014). Yssledovanye sety TCP/IP s prymenenyem osnovnykh alghorytmov aktyvnogho upravlenyja ocheredjju.Systemy upravlinnja, navighaciji ta zv'jazku, 2(30), 87-91.

[9] Dovzhenko, T. P., Storchak, K. P. (2016). Doslidzhennja TCP/IP merezhi z vykorystannjam modyfikovanogho REM-alghorytmu aktyvnogho upravlinnja cherghoju z dynamichno rozshhepljajemoju kharakterystykoju (DSREM). Materialy XXXVII Mizhnarodnoji naukovo-praktychnoji konferenciji “PROBLEMY I PERSPEKTYVY NAUKOVYKh DOSLIDZhENJ”, Chernivci, 1, 12-14.

[10] Ghostev, V. Y., Skurtov, S. N. (2013). Avtomatycheskye systemy aktyvnogho upravlenyja ocheredjju v setjakh TCP/IP.Nezhyn - NGhU ym. Ghogholja, 528. 